\title{
Dâhiliye Hemşirelerinin Kanıta Dayalı Hemşireliğe Yönelik Tutumları
}

\author{
Tuğba MENEKLI*, Medet KORKMAZ**
}

$\ddot{O} z$

Giriş: Kanıta dayalı sağlık hizmeti yaklaşımı, klinik karar verme sürecinde oldukça önemlidir. Bakım sürecinde hemşire tarafından alınan her karar, mevcut en iyi kanıtlara, klinik deneyimlere ve hasta tercihlerine dayanmalıdır. Amaç: Bu araştırmanın amacı dâhiliye kliniklerinde çalışan hemşirelerin kanıta dayalı hemşireliğe yönelik tutumlarının belirlenmesidir. Yöntem: Tanımlayıcı tipteki bu çalışma, Mayıs 2018Aralık 2018 tarihleri arasında Şanlıurfa bölgesindeki hastanelerin dâhiliye kliniklerinde çalışan 964 hemşire ile gerçekleştirildi. Araştırmanın verileri "Hemşire Bilgi Formu” ve "Kanıta Dayalı Hemşireliğe Yönelik Tutum Ölçeği” (KDHYTÖ) ile toplandı. Verilerin analizi SPSS 23.0 programında yapıldı. Bulgular: Hemşirelerin \%65.7'sinin hemşirelik uygulamalarında kanıta dayalı uygulamaları kullanmadıkları ve \%63.1'inin hemşirelik uygulamaları ile ilgili kanıtlara ulaşabileceği kaynakları bilmedikleri saptandı. Hemşirelerin "Kanıta Dayalı Hemşireliğe Yönelik Tutum Ölçeği" toplam puan ortalaması $43.53 \pm 3.08$; kanıta dayalı hemşireliğe yönelik inanç ve beklentiler alt boyut puan ortalaması $23.18 \pm 2.07$, kanıta dayalı uygulama niyeti alt boyut puan ortalaması $11.44 \pm 3.16$ ve kanıta dayalı hemşirelikle ilgili duygular alt boyut puan ortalaması ise $8.91 \pm 2.7$ olarak belirlendi. Yaşı 25 ve altı olan, eğitim durumu lisans ve üzeri düzeyde olan, 1-6 altı yıldır ve sorumlu hemşire olarak çalışan, bilimsel araştırma yapan ve toplantılara katılan hemşirelerin toplam tutum puanlarının istatistiksel olarak anlamlı derecede daha yüksek olduğu belirlendi $(p=0.000)$. Sonuç: Dâhiliye kliniklerinde çalışan hemşirelerin kanıta dayalı hemşireliğe yönelik tutumları orta düzeydedir ve geliştirilmeye gereksinimi vardır.

Anahtar Sözcükler: Hemşire, Kanıta Dayalı Hemşirelik, Tutum, Dahiliye Kliniği.

\section{Abstract}

Internal Medicine Nurses' Attitudes towards Evidence-Based Nursing

Background: Health care approach in evidence is very important in clinical decision making. The care decision is based on the best evidence available, clinical experience and patient preferences, it was decided. Objective: The aim of this study is to ensure that nurses working in internal medicine clinics have evidence-based nursing to determine their attitudes towards. Methods: This descriptive study was conducted between May 2018 and December 2018 with 964 nurses working in hospitals in Sanliurfa. The explanation of the study was collected with "Nurse Information Form" and "Attitude Scale towards Evidence-Based Nursing". The analysis of the data was done in SPSS 23.0 program. Results: It was determined that $65.7 \%$ of the nurses used evidence-specific preferences in their nursing practices and $63.1 \%$ of them did not know if you can access the evidence that includes nursing. The mean score of the eler Evidence Based Nursing Scale of the nurses was 43.53 \pm 3.08 ; Beliefs and expectations for proven nursing are $23.18 \pm 2.07,11.44 \pm 3.16$ and $11.44 \pm 3.16$, respectively. It was determined that the total attitude scores of the nurses aged 25 and under, working as a responsible nurse for 1-6 years, conducting scientific research and attending the meetings were significantly higher. Conclusion: Attitudes of nurses working in treatment clinics towards proven nursing are moderate and need to be improved.

Key Words: Nurse, Evidince-Based Nursing, Attitude, Internal Medicine Clinic.

Geliş tarihi:.18.08.2020

Kabul tarihi: 03.01.2021

anıt, sağlık bakım sistemindeki karar vericilerin ulaşabildiği, uygulamanın bilimsel olarak değerlendirilmesine dayanan bilgidir $(1,2)$. Kanıta dayalı uygulama (KDU), hastanın tıbbi bakımı için karar alma sürecinde konu ile ilgili olarak yayımlanmış güncel ve en iyi kanıtların, hastanın iyileşmesi ve hizmetin iyi bir şekilde planlanması ve yürütülmesi için titizlikle kullanılmasını hedeflemektedir (2,3). Bu terim ilk kez 1992 yılında literatürde yer almaya başlamış ve daha sonra hemşirelik alanındaki çalışmalarda önemi giderek artmaya devam etmiştir $(1,3)$.

Hemşirelik uygulamalarında; girişimlerin etkinliği, değerlendirmelerin doğruluğu ve hassasiyeti, nedensel ilişkilerin gücü, girişimlerin maliyet etkililiği, hasta deneyimleri, inanç ve tutumları gibi sayısız soru üretilebilir (2-4). Bu tür soruların her biri farklı çalışma tasarımlarıyla ele alınabilir. Ancak kanıta dayalı uygulayıcılar için önemli bir zorluk, öne sürülen soruyu cevaplamak için en iyi tasarımın kullanılıp kullanılmadığıdır. Hemşirelik uygulamalarında KDU'da en yaygın kullanılan çalışmalar randomize kontrollü çalışmalar, sistematik incelemeler ve meta-analizlerdir (1-6).

Günümüzde sağlık bakım kalitesinin artırılması ve maliyet-etkili bakım verme çabaları, bilginin yönetimindeki ve sağlık bakım tercihlerindeki değişiklikler, hastaların hatalı uygulama kaygısı ve bilgilendirilme istemlerinde artış, sağlık personeline güvenin azalması ve tüm çabalara rağmen henüz bakımın sadece \%20'sinin kanıta dayalı olması gibi nedenler, kanıta dayalı uygulamaları zorunlu hale getirmiştir $(2,3)$. Hemşirelik uygulamalarının kanıta dayalı olması, bakım kalitesini ve bakım sonuçlarını iyileştirmek, klinik uygulamalarda ve hasta bakım sonuçlarında fark yaratmak, bakımı standardize etmek ve hemşire memnuniyetini artırmak gibi sonuçlar açısından önemlidir $(4,5)$. İletişim teknolojilerinin kullanımındaki artış ile birlikte bilgiye kolay ulaşım ve yeni teknolojik gelişmelerin hayatımıza hızla girmesi, hastaların beklentilerini yükseltmiştir (4-6). Bu tür sebeplerle çağdaş hemşirelik uygulamalarında klinik karar verme sürecinde KDU'lar neredeyse bir zorunluluk haline gelmiştir (3). Sağlık kuruluşlarındaki en kalabalık grup olan hemşirelerin, en iyi kanıtı tanımlamak ve uygulamalarına aktarmak için KDU'ları kavramaları gerekmektedir. Hemşirelerin KDU konusunda tutumlarının belirlenmesi, kanıta dayalı hemşirelik uygulamalarının artırılması ile ilgili stratejilerin geliştirilmesine yardımcı olacaktır. Kanıta dayalı hemşirelik sürecini hızlandıracak stratejilerin geliştirilebilmesi için atılacak ilk adım hemşirelerin konu ile ilgili tutumlarının bilinmesidir (5-7). Dâhiliye kliniklerinde yatan hastaların çoğu kalp yetmezliği, kanser, kronik obstrüktif akciğer hastalığı ve diyabet gibi kronik hastalığa sahip, yoğun bir tedavi ve bakım sürecine gereksinimi olan, tekrarlı hastaneye yatışlara maruz kalabilen ve bazen de terminal dönemde olan hastalardır (5-8). Uzun süreli bakıma gereksinim duyan ve bağımlılık düzeyinin daha yüksek olduğu hasta gruplarına bakım verilen dâhiliye kliniklerinde KDU'ların kullanımı yaşamsal önem arz etmektedir (3-8).

*Dr. Öğretim Üyesi, İnönü Üniversitesi Hemşirelik Fakültesi, İç Hastalıkları Hemşireliği Anabilim Dalı, Malatya. ORCíD: 0000-0002-8291-8274, E-mail: tugbamenekli2013@gmail.com, Tel: 053458206 05, Fax :+90422 5028003 ** Doç. Dr., İnönü Üniversitesi Hemşirelik Fakültesi, İç Hastalıkları Hemşireliği Anabilim Dali, Malatya. ORCiD: 0000-0002-9894-9331, E-mail: medet.korkmaz@inonu.edu.tr 
Araştırma

Bu kliniklerde çalışan hemşirelerin hastalığın ilerlemesini ve komplikasyonların ortaya çıkmasını önleyici girişimleri etkin bir şekilde uygulayabilmesi ve hastalara verilen bakımın etkinliğini ve kalitesini artırmada kanıt temelli uygulamaları kullanması gereklidir (7). Geniş bir hasta grubuna hizmet veren dâhiliye hemşirelerinin ancak KDU'larla hemşirelik bakımını sürdürmesi sonucunda klinikte bakım kalitesini artırması, tıbbi hata olasılığını azaltması, bakımı standardize etmesi, hasta memnuniyetini arttırması ve maliyeti azaltması mümkün olabilecektir $(6,8)$.

$\mathrm{Bu}$ nedenle, dâhiliye kliniklerinde çalışan hemşirelerin KDU’ya yönelik tutumunun belirlenmesi önemlidir. Hemşirelerin kanıta dayalı tutumlarını ve görüşlerini değerlendiren uluslararası düzeyde çalışmaların olmasına ragmen ülkemizde yapılan araştırma sayısının az olduğu ve örneklem sayısının da daha küçük olduğu (min:100;max:255) görülmüştür (1-8). Literatüre daha büyük (n:964) örneklem gruplu çalışmanın kazandırılması açısından böyle bir araştırmanın yapılmasına gerek duyulmuştur.

\section{Amaç}

Bu çalışmanın amacı, dâhiliye kliniklerinde çalışan hemşirelerin, kanıta dayalı uygulamalara yönelik tutumlarını belirlemektir.

\section{Araştırma soruları}

Dahiliye hemşirelerinin KDU’ya yönelik tutumları hangi düzeydedir?

Dahiliye hemşirelerinin tanıtıcı özellikleri KDU tutumunu etkiler mi?

Dahiliye hemşirelerinin bilimsel aktiviteleri KDU tutumunu etkiler mi?

\section{Araştırmanın Tipi ve Yeri \\ Tanımlayıcı nitelikte olan bu çalışma Şanlıurfa ilinde yer alan devlet hastaneleri ve bir üniversite hastanesinde yapıldı. Araştırmanın Evreni/Örneklemi}

Araştırmanın evrenini Şanlıurfa ilinde bulunan toplam 13 devlet ve 1 üniversite hastanesindeki dâhiliye kliniklerinde çalışan tüm hemşireler (N:1253) oluşturdu. Araştırmaya dâhiliye kliniklerinde (Dâhiliye, Kardiyoloji, Nöroloji, Dâhiliye Yoğun Bakım, Gögüs ve Diyaliz) çalışan ve araştırmaya katılmayı kabul eden hemşireler dâhil edildi. Örneklem seçimine gidilmeyerek evrenin tümüne ulaşılmaya çalışıldı. Çalışma sonunda örneklemi Mayıs 2018-Aralık 2018 tarihleri arasında izinli/raporlu olmayan ve araştırmaya katılmayı kabul eden devlet hastanelerinden 754 ve üniversite hastanesinden 210 olmak üzere toplam 964 hemşire oluşturdu. Bu çalışmada toplam katılım oranı \% 77 'dir (964/1253).

\section{Veri Toplama Araçlart}

Veriler, "Hemşire Bilgi Formu” ve "Kanıta Dayalı Hemşireliğe Yönelik Tutum Ölçeği” (KDHYTÖ) kullanılarak toplandı. Hemşire Bilgi Formu

$\mathrm{Bu}$ form, araştırmacılar tarafından literatürden yararlanılarak oluşturuldu (1-8) formda; hemşirelerin "yaş, cinsiyet, medeni durum, eğitim düzeyi, çalışma yılı, çalışma pozisyonu, çalışma şekli, çalıştı̆̆ı vardiya türü, bakım verilen hasta sayısı, mesleki yayınları takip etme, bilimsel toplantılara katılma ve mezuniyet sonrası araştırma yapma durumu"nu belirlemeye yönelik 16 soru yer aldi.

\section{Kanıta Dayalı Hemşireliğe Yönelik Tutum Ölçeği (KDHYTÖ)}

$\mathrm{Bu}$ ölçek, hemşirelerin kanıta dayalı hemşireliğe yönelik tutumlarını ölçmek amacıyla 2011 yılında İspanya'da Ruzafa-Martinez ve arkadaşları tarafından geliştirildi (3). Ölçeğin geçerlik ve güvenirlik çalışması Türkiye' de 2015 yılında Ayhan ve arkadaşları tarafından yapıldı (9). Ölçek, 15 maddeden ve üç alt boyuttan oluşmaktadır. Maddelerin sekizi olumlu (1, 2, 5, 7, 9, 11, 13 ve 14. maddeler) yedisi olumsuz $(3,4,6,8,10,12$ ve 15. maddeler) ifade içermekte; olumsuz maddeler ters çevrilerek kodlanmaktadır.

Beşli likert tipine ( 1 = Hiç katılmıyorum, 2 = Katılmıyorum, 3 = Biraz katılıyorum, $4=$ Katılıyorum, $5=$ Tamamen katılıyorum) göre hazırlanan ölçekten en düşük 15, en yüksek 75 puan alınmaktadır. Ölçekten yüksek puan alınması kanıta dayalı hemşireliğe yönelik tutumun olumlu olduğunu göstermektedir. Ölçeğin üç alt boyutu; Kanıta Dayalı Hemşireliğe Yönelik İnanç ve Beklentiler, Kanıta Dayalı Uygulama Niyeti ve Kanıta Dayalı Hemşirelikle İlgili Duygular Alt Boyutu şeklindedir. İnanç alt boyutu için 7 - 35, uygulama niyeti ve duygular alt boyutları için 4 - 20 aralığındadır. Kanıta Dayalı Hemşireliğe Yönelik İnanç ve Beklentiler Alt Boyutu; hemşirelerin klinik çalışmalarda kanıta dayalı hemşireliğin yararları ile ilgili inanç ve beklentilerine ilişkin maddeleri içermektedir (1, 2, 7, 9, 11, 13, 14. maddeler). Kanıta Dayalı Uygulama Niyeti Alt Boyutu; hemşirelerin kanıta dayalı uygulamaları yapma davranışları veya niyetleri; algılanan engelleri, iş yükü ve eğitim için ayrılan sürenin kanıta dayalı hemşirelik için kullanılmasına ilişkin maddeleri içermektedir (3, 5, 6, 12. maddeler). Kanıta Dayalı Hemşirelikle İlgili Duygular Alt Boyutu; kanıta dayalı hemşireliğe verilen önem düzeyini, kanıta dayalı hemşireliğin klinik uygulamada kullanılmasında sağlanan yararları ve hemşirelerin konuyla ilgili duygularına ilişkin maddeleri içermektedir (4, 8, 10, 15. maddeler). Ölçeğin toplam Cronbach $\alpha$ güvenirlik katsayısı .90’dır $(3,9)$. Bu araştırmada ölçeğin Cronbach alfa iç tutarlılık katsayısı .70 olarak hesaplanmiştır.

\section{Veri Toplama Araçlarının Uygulanması}

"Hemşire Bilgi Formu” ve "KDHYTÖ” Mayıs 2018-Aralık 2018 tarihleri arasında dâhiliye kliniklerinde çalışan ve araştırmaya katılmayı kabul eden hemşirelere araştırmacı tarafından yüz yüze görüşme tekniği kullanılarak uygulandı. Formlar, hemşirelerin çalıştığı kliniklerde araştırmacı ve hemşirenin uygun olduğu herhangi bir zamanda dolduruldu. Formların doldurulması yaklaşık 10 dakika sürdü.

\section{Verilerin Değerlendirilmesi}

Verilerin analizi SPSS 23.0 programında yapıld1. Veriler, tanımlayıcı istatistikler (aritmetik ortalama, standart sapma, minimum, maksimum, sayı ve yüzde), one way anova ve t testi kullanılarak değerlendirildi. İkiden fazla gruplarda farkın hangi gruptan kaynaklandığını belirlemek için post-hoc analiz yöntemlerinden Bonferroni testi kullanıldı. Verilerin normallik analizi Kolmogorov- Smirnov testi ile yapılmış olup istatistiksel anlamlılık $\mathrm{p}<.05$ olarak kabul edildi. 
Araştırma

\section{Araştırmanın Etik Yönü}

Araştırmanın yürütülmesi için öncelikle ülkemizde Türkçe geçerlik ve güvenirlik çalışmasını yapan yazardan e-mail yoluyla yazılı izin alınmıştır. Ayrıca üniversite etik kurulundan (Karar No: 2018-4/13), araştırmanın yapıldığı kurumdan yazılı izin ve hemşirelerden sözlü ve yazılı onay alınmıştır. Makalede araştırma ve yayın etiğine uyulmuştur.

\section{Bulgular}

Araştırma kapsamına alınan hemşirelerin \%65.2'si kadın, \%46.7'si 25 yaş ve altında, \%58.7'si evli ve \%64.1'inin eğitim düzeyi lisans ve üzeridir. Hemşirelerin \%43.1'i 1-6 yıldır, \%70.8'I kadrolu ve \%49.2'si 16-08 vardiyasında \%74.5'i servis hemşiresi olarak çalışmaktadır. Hemşirelerin \%52.4'ü çalıştıkları birimde günde 21 ve üstü sayıda hastaya bakım vermektedir (Tablo 1).

Tablo 1. Dâhiliye Kliniklerinde Çalışan Hemşirelerin Tanıtıcı Özellikleri $(n=964)$

\begin{tabular}{|c|c|c|}
\hline Tanıtıcı Özellikler & $\mathbf{n}$ & $\%$ \\
\hline \multicolumn{3}{|l|}{ Cinsiyet } \\
\hline Kadın & 629 & 65.2 \\
\hline Erkek & 335 & 34.8 \\
\hline \multicolumn{3}{|l|}{ Yaş (min:20.57 max:40.91) } \\
\hline 25 yaș ve $\downarrow$ & 450 & 46.7 \\
\hline $26-36$ yaş & 391 & 40.6 \\
\hline 37 ve $\uparrow$ & 123 & 12.7 \\
\hline \multicolumn{3}{|l|}{ Eğitim düzeyi } \\
\hline Lise & 247 & 25.6 \\
\hline Ön lisans & 99 & 10.3 \\
\hline Lisans ve üzeri & 618 & 64.1 \\
\hline \multicolumn{3}{|l|}{ Medeni durum } \\
\hline Evli & 566 & 58.7 \\
\hline Bekâr & 398 & 41.3 \\
\hline \multicolumn{3}{|l|}{ Çalışma yılı (min:1.3 max:22.6) } \\
\hline $1-6 \mathrm{y} 11$ & 416 & 43.1 \\
\hline $7-12$ y1l & 236 & 24.5 \\
\hline $13-18$ y1l & 204 & 21.2 \\
\hline 19 ve $\uparrow$ & 108 & 11.2 \\
\hline \multicolumn{3}{|l|}{ Çalışma pozisyonu } \\
\hline Servis hemşiresi & 718 & 74.5 \\
\hline Sorumlu hemşire & 246 & 25.5 \\
\hline \multicolumn{3}{|l|}{ Çalıştığı vardiya türü } \\
\hline $8-16$ & 304 & 31.5 \\
\hline $16-08$ & 474 & 49.2 \\
\hline $08-08 / 24-08$ & 186 & 19.3 \\
\hline \multicolumn{3}{|l|}{ Çalıșma șekli } \\
\hline Kadrolu & 683 & 70.8 \\
\hline Sözleşmeli & 281 & 29.2 \\
\hline \multicolumn{3}{|l|}{ Bakım verdiği hasta sayısı /günde } \\
\hline 20 ve $\downarrow$ & 459 & 47.6 \\
\hline 20 ve $\uparrow$ & 505 & 52.4 \\
\hline
\end{tabular}

Hemşirelerin; hemşirelik uygulamalarında en fazla kullandıkları bilgi kaynaklarının \%30.9 oranında deneyimli hemşirelerden alınan bilgiler olduğu, hemşirelik uygulamalarında KDU'ları sadece \%34.3'ünün kullandığ1 ve \%63.1'inin hemşirelik uygulamaları ile ilgili kanıtlara ulaşabileceği kaynakları bilmediği saptandı. Katılımcıların \%34.3’ü bilimsel toplantılara katıldığını, \%.27.6'sı mezun olduktan sonra hemşirelik ile ilgili bilimsel araştırma yaptığını, \%64.3'ü herhangi bir mesleki derneğe üye olmadığını ve \%59.5'i yabancı dil (İngilizce) bilmediğini belirtti (Tablo 2). 
Tablo 2. Hemşirelerin Bilimsel Aktiviteleri $(n=964)$

\begin{tabular}{|c|c|c|}
\hline Hemşirelerin Bilimsel Aktiviteleri & n & $\%$ \\
\hline \multicolumn{3}{|c|}{ Hemșirelik uygulamalarında kullanılan bilgi kaynakları } \\
\hline Hizmet içi eğitim & 243 & 25.2 \\
\hline Hemşirelik eğitimi sırasında alınan bilgiler & 131 & 13.6 \\
\hline Deneyimli hemşirelerden alınan bilgiler & 298 & 30.9 \\
\hline İnternet & 200 & 20.8 \\
\hline Bilimsel dergi-kitaplar & 92 & 9.5 \\
\hline \multicolumn{3}{|l|}{ Kanıta dayalı uygulamaları kullanma durumu } \\
\hline Evet & 331 & 34.3 \\
\hline Hayır & 633 & 65.7 \\
\hline \multicolumn{3}{|l|}{ Kaynaklara ulaşmayı bilme durumu } \\
\hline Evet & 356 & 36.9 \\
\hline Hayır & 608 & 63.1 \\
\hline \multicolumn{3}{|l|}{ Bilimsel toplantılara katılma durumu } \\
\hline Evet & 340 & 35.3 \\
\hline Hayır & 624 & 64.7 \\
\hline \multicolumn{3}{|l|}{ Bilimsel araştırma yapma durumu } \\
\hline Evet & 266 & 27.6 \\
\hline Hayır & 698 & 72.4 \\
\hline \multicolumn{3}{|l|}{ Herhangi bir mesleki derneğe üye olma durumu } \\
\hline Evet & 340 & 35.3 \\
\hline Hayır & 624 & 64.7 \\
\hline \multicolumn{3}{|l|}{ Yabancı dil bilme durumu } \\
\hline Evet & 390 & 40.5 \\
\hline Hayır & 574 & 59.5 \\
\hline
\end{tabular}

Dâhiliye kliniklerinde çalışan hemşirelerin kanıta dayalı hemşireliğe yönelik tutumları incelendiğinde; hemşirelerin KDHYTÖ toplam puan ortalaması $43.53 \pm 3.08$; KDU inanç ve beklentiler alt boyut puan ortalaması 23.18 \pm 2.07 , KDU niyeti alt boyut puan ortalaması $11.44 \pm 3.16$ ve KDU duygular alt boyut puan ortalamasi $8.91 \pm 2.71$ olarak saptand1 (Tablo 3).

Tablo 3. Hemşirelerin "KDHYTÖ” ve Alt Boyutları Puan Ortalamaları $(n=964)$

\begin{tabular}{|c|c|c|c|}
\hline & $\begin{array}{l}\text { Alt ve } \\
\text { Üst } \\
\text { Değer }\end{array}$ & $\begin{array}{l}\text { Ölçekten Alınan } \\
\text { Alt ve Üst Değer }\end{array}$ & $\begin{array}{c}\text { Her bir ölçek için } \\
\text { ortalama puanlar } \\
\qquad \overline{\mathrm{X}} \pm \mathrm{SS}\end{array}$ \\
\hline $\begin{array}{l}\text { Kanıta Dayalı Hemşireliğe Yönelik İnanç ve } \\
\text { Beklentiler }\end{array}$ & $7-35$ & 15-27 & $23.18 \pm 2.07$ \\
\hline Kanıta Dayalı Uygulama Niyeti & $4-20$ & $6-16$ & $11.44 \pm 3.16$ \\
\hline Kanıta Dayalı Hemşirelikle İlgili Duygular & $4-20$ & $4-14$ & $8.91 \pm 2.71$ \\
\hline KDHYTÖ Toplam Puan & $15-75$ & $22-62$ & $43.53 \pm 3.08$ \\
\hline
\end{tabular}

Hemşirelerin tanıtıcı özellikleri ve bilimsel aktiviteleri ile KDHYTÖ toplam ve alt boyutlarına ait dağılım incelendiğinde; medeni durum, çalıştığı vardiya türü, çalışma şekli, bakım verdiği günlük hasta sayısı, kullanılan bilgi kaynakları, KDU'ları kullanma, kaynaklara ulaşmayı bilme ve yabancı dil bilme durumu ile ölçek toplam ve alt boyutları arasında istatistiksel olarak anlamlı fark olmadığı bulunmuştur $(\mathrm{p}>.05)$. Ayrıca istatistiksel olarak anlamlı bir fark olduğu bulunan değişkenlere bakıldığında ise; KDHYTÖ toplam puan ortalamalarının sadece herhangi bir mesleki derneğe üye olma durumuna göre dağılımı anlamlı farklılık göstermedi $(\mathrm{p}=.433)$. Toplam puan ortalamalarının diğer tanıtıcı özelliklerin tümüne göre anlamlı derecede farklı dağılım gösterdiği saptandı. Yapılan post-hoc analizinde; yaşı 25 ve altı olan, eğitim durumu lisans ve üzeri düzeyde olan, 1-6 altı yıldır ve sorumlu hemşire olarak çalışan, bilimsel araştırma yapan ve toplantılara katılan hemşirelerin toplam tutum puanlarının istatistiksel olarak anlamlı derecede daha yüksek olduğu belirlendi $(\mathrm{p}=.000)$. Alt boyut puanlarının tümünün hemşirelerin eğitim durumlarına göre dağılımları arasında anlamlı fark saptandı. Ek olarak, KDU niyeti alt boyut puanlarının herhangi bir mesleki derneğe üye olma durumuna göre dağılımı da anlamlı farklılık gösterdi $(p=.019)$. Yapılan post-hoc analizinde; lisans ve üzeri eğitim düzeyi olan ve herhangi bir mesleki derneğe üye olan grubun puan ortalamalarının daha yüksek olduğu belirlendi $(\mathrm{p}=.000)$ (Tablo 4). 
Tablo 4. Hemşirelerin Tanıtıcı Özellikleri ve Bilimsel Aktiviteleriİle KDHYTÖ Alt Boyutlarına Ait Puan Ortalamalarının Dağılımı(n = 964)

\begin{tabular}{|c|c|c|c|c|c|c|c|c|}
\hline \multirow[t]{2}{*}{$\begin{array}{l}\text { Hemşirelerin Tanıtıcı Özellikleri } \\
\text { ve Bilimsel Aktiviteleri }\end{array}$} & \multicolumn{2}{|c|}{$\begin{array}{l}\text { Kanıta Dayalı Hemşireliğe } \\
\text { Yönelik İnanç ve Beklentiler }\end{array}$} & \multicolumn{2}{|c|}{$\begin{array}{l}\text { Kanıta Dayalı } \\
\text { Uygulama Niyeti }\end{array}$} & \multicolumn{2}{|c|}{$\begin{array}{c}\text { Kanıta Dayalı } \\
\text { Hemşireliğe Yönelik } \\
\text { Duygular }\end{array}$} & \multicolumn{2}{|c|}{ KDHYTÖ Toplam Puan } \\
\hline & $\mathbf{X} \pm \mathbf{S S}$ & Test ve $p$ & $\mathrm{X} \pm \mathrm{SS}$ & Test ve p & $\mathrm{X} \pm \mathrm{SS}$ & Test ve $p$ & $\mathbf{X} \pm \mathrm{SS}$ & Test ve $p$ \\
\hline $\begin{array}{l}\text { Yaş grubu } \\
\qquad \begin{array}{l}25 \text { yaş ve altı } \\
26-36 \text { yaş } \\
37 \text { ve üzeri }\end{array}\end{array}$ & $\begin{array}{l}24.02 \pm 2.71 \\
22.69 \pm 1.80 \\
21.05 \pm 1.15\end{array}$ & $\begin{array}{l}\mathrm{F}=0.572 \mathrm{p} \\
=.803\end{array}$ & $\begin{array}{l}10.29 \pm 3.35 \\
9.76 \pm 3.50 \\
9.50 \pm 1.87\end{array}$ & $\begin{array}{l}F=1.394 \\
p=.605\end{array}$ & $\begin{array}{c}10.51 \pm 3.70 \\
9.94 \pm 2.81 \\
9.05 \pm 1.04 \\
\end{array}$ & $\begin{array}{l}F=0.201 p \\
=.774\end{array}$ & $\begin{array}{l}46.34 \pm 9.17^{\mathrm{a}} \\
43.93 \pm 7.51^{\mathrm{b}} \\
32.41 \pm 4.40^{\mathrm{b}}\end{array}$ & $\begin{array}{l}\mathrm{F}=1.250 \\
\mathbf{p}=\mathbf{. 0 0 5} *\end{array}$ \\
\hline $\begin{array}{l}\text { Eğitim düzeyi } \\
\text { Lise mezunu } \\
\text { Önlisans mezunu } \\
\text { Lisans mezunu ve üzeri }\end{array}$ & $\begin{array}{l}19.08 \pm 2.21^{\mathrm{b}} \\
20.13 \pm 3.10^{\mathrm{b}} \\
28.75 \pm 2.35^{\mathrm{a}}\end{array}$ & $\begin{array}{l}F=1.987 \\
\mathbf{p}=\mathbf{. 0 2 0} *\end{array}$ & $\begin{array}{l}11.31 \pm 2.71^{\mathrm{b}} \\
12.00 \pm 1.16^{\mathrm{b}} \\
15.09 \pm 1.76^{\mathrm{a}}\end{array}$ & $\begin{array}{l}F=2.062 \\
\mathbf{p}=\mathbf{. 0 1 1} *\end{array}$ & $\begin{array}{l}10.30 \pm 3.23^{\mathrm{b}} \\
11.65 \pm 1.85^{\mathrm{b}} \\
16.03 \pm 1.34^{\mathrm{a}}\end{array}$ & $\begin{array}{l}F=2.169 \\
\mathbf{p}=\mathbf{. 0 3 4} *\end{array}$ & $\begin{array}{l}34.07 \pm 9.17 \mathrm{~b} \\
39.93 \pm 7.59^{\mathrm{b}} \\
55.81 \pm 4.08^{\mathrm{a}}\end{array}$ & $\begin{array}{l}\mathrm{F}=3.285 \\
\mathbf{p}=\mathbf{. 0 2 1} *\end{array}$ \\
\hline $\begin{array}{l}\text { Çalışma y1lı } \\
\qquad \begin{array}{l}1-6 \text { y1l } \\
7-12 \text { yıl } \\
13-18 \text { yıl } \\
19 \text { ve üzeri }\end{array}\end{array}$ & $\begin{array}{l}27.51 \pm 1.01 \\
23.92 \pm 2.70 \\
19.07 \pm 3.16 \\
18.14 \pm 3.37\end{array}$ & $\begin{array}{l}\mathrm{F}=3.346 \mathrm{p} \\
=.691\end{array}$ & $\begin{array}{l}14.04 \pm 2.82 \\
13.61 \pm 2.27 \\
13.02 \pm 3.19 \\
12.13 \pm 1.90\end{array}$ & $\begin{array}{l}F=2.794 p \\
=.305\end{array}$ & $\begin{array}{c}10.00 \pm 1.00 \\
9.65 \pm 2.39 \\
8.88 \pm 3.76 \\
8.53 \pm 1.20\end{array}$ & $\begin{array}{l}\mathrm{F}=3.222 \mathrm{p} \\
=.674\end{array}$ & $\begin{array}{l}55.00 \pm 2.82^{\mathrm{a}} \\
51.48 \pm 4.58^{\mathrm{b}} \\
49.34 \pm 4.07^{\mathrm{b}} \\
48.20 \pm 3.09^{\mathrm{b}}\end{array}$ & $\begin{array}{l}\mathrm{F}=3.071 \\
\mathbf{p}=\mathbf{. 0 2 0} *\end{array}$ \\
\hline $\begin{array}{l}\text { Çalışma pozisyonu } \\
\text { Servis hemşiresi Sorumlu } \\
\text { hemşire }\end{array}$ & $\begin{array}{l}25.15 \pm 5.14 \\
25.51 \pm 4.68\end{array}$ & $\begin{array}{l}\mathrm{t}=0.448 \\
\mathrm{p}=.692\end{array}$ & $\begin{array}{l}11.45 \pm 3.01 \\
15.94 \pm 3.02 \\
\end{array}$ & $\begin{array}{l}\mathrm{t}=0.977 \\
\mathrm{p}=.530\end{array}$ & $\begin{array}{l}10.62 \pm 3.49 \\
13.39 \pm 3.42\end{array}$ & $\begin{array}{l}t=0.401 \\
p=.689\end{array}$ & $\begin{array}{l}43.22 \pm 9.65^{\mathrm{b}} \\
53.84 \pm 9.23^{\mathrm{a}}\end{array}$ & $\begin{array}{l}t=0.392 \\
\mathbf{p}=\mathbf{. 0 2 1} *\end{array}$ \\
\hline $\begin{array}{l}\text { Bilimsel araştırma yapan } \\
\text { Evet } \\
\text { Hayır }\end{array}$ & $\begin{array}{l}19.42 \pm 4.72 \\
14.30 \pm 5.01\end{array}$ & $\begin{array}{l}\mathrm{t}=0.151 \\
\mathrm{p}=.819\end{array}$ & $\begin{array}{l}12.78 \pm 2.78 \\
12.68 \pm 3.19\end{array}$ & $\begin{array}{l}\mathrm{t}=0.201 \\
\mathrm{p}=.841\end{array}$ & $\begin{array}{l}11.57 \pm 3.26 \\
10.43 \pm 3.58\end{array}$ & $\begin{array}{l}\mathrm{t}=0.236 \\
\mathrm{p}=.814\end{array}$ & $\begin{array}{l}41.78 \pm 8.66^{\mathrm{a}} \\
30.42 \pm 9.90^{\mathrm{b}}\end{array}$ & $\begin{array}{l}\mathrm{t}=0.230 \\
\mathbf{p}=\mathbf{. 0 3 0} *\end{array}$ \\
\hline $\begin{array}{l}\text { Bilimsel toplantılara katılma } \\
\text { Evet } \\
\text { Hayır } \\
\end{array}$ & $\begin{array}{l}28.08 \pm 4.58 \\
26.04 \pm 4.00\end{array}$ & $\begin{array}{l}\mathrm{F}=1.781 \mathrm{p} \\
=.153\end{array}$ & $\begin{array}{l}14.25 \pm 3.16 \\
11.86 \pm 2.53\end{array}$ & $\begin{array}{l}\mathrm{F}=0.832 \mathrm{p} \\
=.186\end{array}$ & $\begin{array}{l}9.66 \pm 3.55 \\
8.59 \pm 4.12 \\
\end{array}$ & $\begin{array}{l}F=1.101 p \\
=.351\end{array}$ & $\begin{array}{l}51.00 \pm 9.10^{\mathrm{a}} \\
39.50 \pm 8.66^{\mathrm{b}}\end{array}$ & $\begin{array}{l}F=1.624 \\
p=.001 *\end{array}$ \\
\hline $\begin{array}{l}\text { Herhangi bir mesleki derneğe üye oln } \\
\text { durumu } \\
\qquad \begin{array}{l}\text { Evet } \\
\text { Hayır }\end{array}\end{array}$ & $\begin{array}{l}21.80 \pm 4.58 \\
19.11 \pm 4.65\end{array}$ & $\begin{array}{l}\mathrm{F}=1.086 \mathrm{p} \\
=.365\end{array}$ & $\begin{array}{c}13.15 \pm 2.55^{\mathrm{a}} \\
9.15 \pm 2.87^{\mathrm{b}}\end{array}$ & $\begin{array}{l}\mathrm{F}=0.592 \mathrm{p} \\
=\mathbf{. 0 1 9} *\end{array}$ & $\begin{array}{c}10.80 \pm 3.13 \\
9.84 \pm 3.38\end{array}$ & $\begin{array}{l}\mathrm{F}=0.421 \mathrm{p} \\
=.793\end{array}$ & $\begin{array}{l}41.36 \pm 9.45 \\
39.22 \pm 9.71\end{array}$ & $\begin{array}{l}\mathrm{F}=0.958 \\
\mathrm{p}=.433\end{array}$ \\
\hline
\end{tabular}

KDHYTÖ, Kanıta Dayalı Hemşireliğe Yönelik Tutum Ölçeği

*Tekrarlı ölçümlerde varyans analizi

**Aynı harfler farkın olmadığını, farklı harfler ise farkın olduğunu göstermektedir 


\section{Tartışma}

Dahiliye kliniklerinde çalışan hemşirelerin KDU'lara yönelik tutumlarını belirlemek için yapılan bu çalışmada, hemşirelerin KDHYTÖ tutumlarının orta düzeyde $(43.53 \pm 3.08)$ olduğu saptandı. Hemşirelerin tutumunun belirlenmesi ve olumlu yönde değiştirilmesinin KDU'ların hayata geçirilmesi açısından önemli olduğu belirtilmektedir (10-12). Hemşirelerin KDU'ya yönelik tutumlarının incelendiği araştırmalar incelendiğinde; çoğu araştırma da çalışmamızın sonuçları gibi KDU puan ortalamasının orta düzeyde olduğu belirtilirken (46.48 \pm 4.90$)(11-18)$ az sayıda araştırmada ise KDÜ puan ortalamasının orta düzeyin üzerinde $(57.01 \pm 2.20)$ olduğu bildirilmektedir (12-15). KDU ile ilgili araştırmaların genelinde "olumlu tutumun" önemi vurgulanmış ve uygulamaya aktarma çalışmalarında bu olumlu tutumun sürdürülmesi gerektiği belirtilmiştir (13-17). Hemşirelerin hasta bakımlarını KDU temelli yapması; bakım kalitesini yükseltmek ve sonuçlarını iyileştirmek, klinik uygulamalarda ve hasta bakım sonuçlarında fark yaratmak, bakımı standardize etmek, hemşire ve hasta memnuniyetini artırmak gibi sonuçlar açısından önemlidir (20-23). Ayrıca hemşirelik uygulamalarının bilimselleşmesini sağlamak için KDU'ya dayalı olarak gerçekleştirilmesi gereklidir $(4,16)$. Bu nedenle çalışmamızda, hemşirelerin tutumlarının orta düzeyde olması, hemşirelerin KDU’ya ilişkin bilgi/beceri ve uygulamalarda eksikliklerinin olduğunu ve desteklenmeye gereksinimleri olduğunu düşündürmektedir.

KDHYTÖ inanç ve beklentiler alt boyutu, hemşirelerin klinik çalışmalarda kanıta dayalı hemşireliğin yararları ile ilgili inanç ve beklentilerini içermektedir $(22,24)$. KDU'da hemşirelerin, KDU ile ilgili inançları, KDU rehberlerinin kliniğe entegre edilmesinde etkili olmaktadır (24-27). Çalışmamızda, dâhiliye hemşirelerinin KDU’ya yönelik inanç ve beklentilerinin orta düzey de olduğu $(23.18 \pm 2.07)$ belirlenmiştir. Literatür incelendiğinde; hemşirelerin KDU’ya karşı olumlu bir tutuma sahip oldukları, ancak kanıta dayalı rehberlerdeki uygulamaları daha az kapsamda klinik uygulamaya aktardıkları, KDU'ya yönelik tutum ile KDU'nın kliniğe aktarılmasına ilişkin inançlar arasında olumlu yönde bir ilişki olduğu ve KDU'ya yönelik inançların, KDU'ların kliniğe aktarılması üzerinde büyük etkiye sahip olduğu görülmektedir (20-26). İnanç alt boyutunda olumlu tutumun yüksek olması hemşirelerin KDU için harekete geçmeye hazır olduklarının göstergesidir $(25,26)$. Bu bağlamda, çalışmamıza katılan dâhiliye hemşirelerinin KDU'ya yönelik tedavi ve bakım girişimlerini yapmak için orta düzeyde kendilerini hazır hissettikleri düşünülmektedir.

KDHYTÖ uygulama niyeti alt boyutu; hemşirelerin KDU'ları yapma davranışları veya niyetleri, algılanan engelleri, iş yükü ve eğitim için ayrılan sürenin kanıta dayalı hemşirelik için kullanılmasını içermektedir. Çalışmamızda, dâhiliye hemşirelerinde uygulama niyet alt boyutunun orta düzeyin altında olduğu bulunmuştur. Dikmen ve arkadaşlarının (2018) yaptığ1 çalışmada yoğun bakım hemşirelerinin KDU'ya yönelik uygulama niyetlerinin orta düzeyin altında (10.06 \pm 1.37$)$ olduğu belirlenmiştir (15). Üniversite hastanesinde çalışan dahiliye hemşireleri ile yapılan bir başka araştırmada ise uygulama niyeti alt boyutunun $15.51 \pm 2.52$ olmak üzere orta düzeyin üstünde bulunduğu belirtilmektedir (19). Bizim çalışmamız da örneklem çoğunluğunu devlet hastanelerin de çalışan hemşirelerin oluşturması, uygulama niyeti puan ortalamasının orta düzeyin altında olması sonucuna bir neden olabileceğini düşündürmektedir. Ayrıca çalışmamızda hemşirelerin kanıt temelli uygulama niyetlerinin orta düzeyin altında olması, hemşirelerin uygulamada algıladıkları engellerden; yetersiz zaman ve yetersiz kaynaklardan kaynaklandığını düşündürmüştür. Hemşirelerin bu tutumlarını olumlu yönde etkilemek için yöneticilerin ve eğitimcilerin KDU ilkelerine bağlı olmaları, kaynak sağlamaları ve bunu hayata geçirmeleri için destekleyici bir ortam oluşturmaları gerektiği bildirilmektedir (22-26).

KDHYTÖ duygular alt boyutu; kanıta dayalı hemşireliğe verilen önem düzeyini, kanıta dayalı hemşireliğin klinik uygulamada kullanılmasında sağlanan yararları ve hemşirelerin konuyla ilgili duygularını içermektedir. Çalışmamızda dâhiliye hemşirelerinin duygu alt boyutu ortanın altındadır (8.91 \pm 2.71$)$. Yılmaz ve arkadaşları (2018), dâhili ve cerrahi hemşirelerinin kanıta dayalı hemşireliğe yönelik duygularının düşük (6.03 \pm 1.99$)$, Daştan ve Hindistan (2018) ise dâhiliye hemşirelerinin kanıta dayalı hemşireliğe yönelik duygularının orta düzeyin üstünde olduğunu (15.28 \pm 3.59$)$ olduğunu saptamıştır $(17,19)$. Bu araştırmalarla karşılaştırıldığında bu çalışmanın puan ortalamalarının birbirinden farklı olduğu görülmektedir. Bununla birlikte bu puan ortalamaları örneklem seçimi, kullanılan ölçek, uygulama yapılan hastanenin büyüklüğ̈̈ gibi faktörler göz önüne alındığında farklı çalışmalarda farklı sonuçlar da gösterebilecektir. Bizim çalışmamızda hemşirelerin KDU'ların klinik uygulamada kullanılmasında sağlanan yararlar konusundaki duygularının olumsuz olması, KDU'nun hemşirelik bakım çıktıları üzerine olan olumlu etkisi hakkında bilgilerinin yeterli olmadığını düşündürmüştür (27-30). Nitekim araştırmamız kapsamında ki hemşirelerin büyük çoğunluğunun klinikte KDU kullanmadığı bulunmuştur.

Araştırma kapsamına alınan hemşirelerden 25 yaş ve altında olan, sorumlu hemşire olan ve çalışma deneyimi 1-6 yıl arasında olan hemşirelerin kanıt temelli uygulamalara yönelik tutumları daha yüksektir. Literatür incenlendiğinde; araştırmamızın sonuçlarına benzer şekilde 20-25 yaş grubu ve 1-5 yıldır çalışan hemşirelerin KDU tutumlarının daha olumlu olduğu belirtilmiştir (26-32). Mezuniyet tarihinin yakın olmasının alınan eğitimin daha iyi hatırlanmasını sağlaması, hemşirelik eğitimine son yıllarda KDU kavramının entegre edilmesi ve yeni işe başlayanların KDU kullanımı hakkında daha çok istekli olması hemşirelerin KDU tutumlarını olumlu yönde etkilemektedir (31-33). Malik ve arkadaşları (2015) ile Youssef ve arkadaşları (2018) sorumlu hemşire pozisyonunda çalışan hemşirelerin KDU tutumlarının daha olumlu olduğunu belirtmektedir $(32,33)$. Bizim araştırmamız da literatür ile benzerlik göstermektedir, bu sonucun sorumlu hemşirelerin çoğunlukla gündüz ve hafta içi çalışması nedeniyle literatür incelemesine daha çok firsa tbulabilmesi, primer olarak direkt hasta bakımı yerine klinik bakım protokollerini servis hemşiresine göre daha yakından takip etmesi ile ilişkili olduğu düşünülmektedir (23-25). KDHYTÖ toplam ve tüm alt boyut puan ortalamalarının lisans ve üzeri eğitim düzeyi olan grupta daha yüksek olduğu belirlenmiştir. Hem ulusal hem de uluslararası literatürde, benzer sonuçların elde edildiği çalışmalar bulunmuştur (22-32). Literatürde eğitim seviyesinin uzaması ile birlikte KDU'lara ilişkin en doğru ve güncel bilginin öğrenildiği belirtilmektedir (20-24). Bu amaçla hemşirelik eğitimlerinde KDU ile ilgili bilgilere daha çok yer verilmesi gerektiği düşünülebilir.

Araştırma yapan, bilimsel toplantılara katılan ve mesleki derneklere üye olan hemşirelerin KDHYTÖ puanları daha yüksektir. Hemşirelerde KDU ile ilgili literarür incelendiğinde; çalışmamızın bulgusuna benzer sonuçlar bulunmuştur (28-34). Hemşirelik mesleğinin istenen seviyelere gelmesi ancak bilimsel uygulamalar ile mümkün olacaktır. Bilimsel etkinliklere 
Araştırma

katılma ve takip etme hemşirelerin kanıt kullanma becerisini geliştiren bir süreç olduğu düşünülmektedir. Bilimsel araştırmalar ve toplantılar, hemşirelerin mesleki gelişiminde etkin rol oynadığı gibi hemşireler arasında bilimsel bilgi paylaşımını artırmada dolayısıyla KDU tutumunun olumlu seviyeye ulaştırılmasında önemli bir yere sahiptir (33-35). Ayrıca hemşirelik dernekleri, güncel araştırma sonuçlarını takip edip sonuçları duyurmak için çalışmalar yapmaktadır (32-34). Çalışmamızda, derneklere üye hemşirelerin KDU tutumlarının yüksek olmasının hemşirelerin dernekler aracılığıyla KDU hakkında bilimsel araştırmaları takip edebilmeleri ile ilişkili olduğunu düşündürmektedir.

\section{Sonuç ve Öneriler}

Bu çalışma, örneklemi oluşturan hemşire sayısının büyüklüğü $(n=964)$ gözönüne alınarak ülkemizde dahiliye kliniklerinde çalışan hemşirelerin kanıta dayalı hemşireliğe yönelik tutumlarının incelendiği sınırlı çalışmalardan biri olarak KDU'ya ilişkin veriler sağlamaktadır.

Yapılan bu çalışma sonucunda; dâhili kliniklerde çalışan hemşirelerin kanıta dayalı hemşireliğe yönelik tutumlarının orta düzeyde olduğu, hemşirelerin bazı tanıtıcı (yaş, eğitim düzeyi, çalışma yılı ve çalışma pozisyonu) ve bilimsel aktivitelere ilişkin (bilimsel araştırma yapma, toplantılara katılma ve derneğe üye olma durumu) özelliklerinin KDU'ya yönelik tutumlarını olumlu yönde etkilediği saptanmıştır. Bu sonuçlar doğrultusunda, öncelikle kanıtların nasıl elde edildiği ve klinik uygulamaya nasıl aktarılabileceği konusunda farkındalığı arttırmak için dahiliye hemşirelerine hizmetiçi eğitim programları düzenlenmelidir. Hemşirelerin araştırma yapabilmesi, bilimsel toplantılara katılabilmesi için uygun firsatların sağlanması ek olarak hemşirelik derneklerine üyeliklerin gerçekleştirilmesi için teşvik edilmesi önerilmektedir.

\section{Kisıtlılıklar}

$\mathrm{Bu}$ araştırmanın başlıca iki kısıtı bulunmaktadır. Birincisi; sadece bir ilde yapılmış olmasıdır. Bundan dolayı araştırmanın sonuçları sadece bu ilde bulunan hastanelerde çalışan dâhiliye hemşireleri için genellenebilir. İkincisi; araştırma verilerinin yüz yüze görüşme yöntemiyle toplanması nedeniyle verilerin güvenilirliği görüşmecilerin verdikleri bilgilerle sınırlıdır. Son olarak ise; verilerin sadece hemşirelerin ifadelerinden elde edilmesi ve gözleme dayalı bulgular içermemesidir.

\section{Sonuçların Uygulamada Kullanımı}

Mesleki profesyonelleşmenin en önemli şartı bilimsel verilerin kullanılması ve sonuçların mesleğe yansıtılmasıdır. Hemşirelikte teori ve uygulamanın bir bütün olarak klinik uygulamalara aktarılması meslek elemanlarının işbirliği ile sağlanabilecektir. Bu nedenle hemşirelerin eğitim sürecinde KDU’larla ilgili tutumlarının belirlenmesi bu konu ile ilgili veri sağlanmasında ve farkındalık oluşturulmasında oldukça önem kazanmaktadır. Bu çalışma, dahiliye hemşirelerinin kanıta dayalı hemşireliğe yönelik tutumlarını ve etkileyen faktörlerini açıklayarak hemşirelik literatürüne katkı sağlayacak ve elde edilen bulgular hemşirelikte KDU'ya yönelik yapılacak araştırma ve eğitim programlarının düzenlenmesi konusuna katkı sağlayacaktır.

\section{Çıkar Çatışması}

Yazarların birbirleri üzerinde herhangi bir çıkar çatışması yoktur.

\section{Bilgilendirme}

Yazarların katkı oranı beyanı şöyledir: fikir/kavram TM; tasarım MK; Denetleme/danışmanlık MK; veri toplama ve işleme, analiz ve yorum TM, MK; kaynak taraması: TM, MK; makalenin yazımı: TM; eleştirel düşünme: MK; araştırmanın bütçesi: TM, MK.

Araştırma ile ilgili herhangi bir projeden ya da firmadan destek alınmamıştır.

Araştırmanın bütçesi araştırmacılar tarafindan karşılanmıştır.

Ayrıca sorumlu olduğumuz araştırmada herhangi bir firma ile çıkar ilişkisi bulunmamaktadır.

Araştırmanın yapılabilmesi için bir üniversitenin girişimsel olmayan araştırmalar etik kurulundan (Karar No: 2018-4/13) izin alınmıştır.

\section{Kaynaklar}

1. Abu Hasheesh MO, AbuRuz ME. Knowledge, attitude and practice of nurses towards evidence- based practice at AlMedina. KSA. JMJ 2017;51(2):47-56.

2. Intas G, Kostagiolas P, Zavras D, Chalari E, Stergiannis P, Toylia G. Information-seeking behavior of Greek nursing students: a questionnaire study. Comput Inform Nurs 2017;35(2):109-114.

3. Ruzafa-Martinez M, Lopez-Iborra L, MadrigalTorres M. Attitude towards evidence-based nursing questionnaire: development and psychometric testing in Spanish community nurses. J Eval Clin Pract 2011;17:664-70.

4. Cosme S, Milner KA, Wonder A. Benchmarking of prelicensure nursing students'evidence-based practice knowledge. Nurse Educator 2018;43(1):50-53.

5. Wallace R, Vanhook P. The importance of evidence-based practice. The Tennessee Nurse, 2016;78(4):11.

6. Aburuz ME, Abu Hayeah H, Al-Dweik G, Al-Akash HY. Knowledge, attitudes, and practice about evidence-based practice: a Jordanian study. Health Science Journal 2017;11(2):1-8.

7. Dalheim A, Harthug S, Nilsen RM, Nortvedt MW. Factors influencing the development of evidence- based practice among nurses: a self-report survey. BMC Health Serv Res 2012;12:367.

8. Korkmaz M. Kronik Hastalıklarda kanıta dayalı uygulamalar. İçinde Ovayolu N, Ovayolu Ö, Temel İç Hastalıkları Hemşireliği ve Farklı Boyutlarıyla Kronik Hastalıklar. Adana: Nobel Yayın Dağıtım; 2015;782-791.

9. Ayhan Y, Kocaman G, Bektaş M. Kanıta dayalı hemşireliğe yönelik tutum ölçeğì"nin Türkçe'ye uyarlanması: geçerlik ve güvenirlik çalışması. Hemşirelikte Araştırma Geliştirme Dergisi 2015;17:21-35. 
Araştırma

10. Arslan FT, Çelen R. Hemşirelik öğrencilerinin kanıta dayalı hemşireliğe yönelik tutumlarının belirlenmesi. Sürekli Tıp Eğitimi Dergisi 2018;27(2):99-106.

11. Vortherms J, Spoden B, Wilcken J. From evidence to practice: developing an outpatient acuity-based staffing model. CJON 2015;19(3):332-337.

12. Thorsteinsson, HS. Icelandic nurses' beliefs, skills, and resources associated with evidence-based practice and related factors: a national survey. Worldviews on Evidence-Based Nursing 2013;10(2):116-126.

13. Reid J, Briggs J, Carlisle S, Scott D, Lewis C. Enhancing utility and understanding of evidence based practice through undergraduate nurse education. BioMed Central Nursing 2017;16: 8.

14. Kyriakoulis K, Patelarou A, Laliotis A, Wan AC, Matalliotakis M, Tsiou C. Educational strategies for teaching evidencebased practice to undergraduate health students: systematic review. J Educ Eval Health Prof 2016; 13: 34.

15. Dikmen Y, Filiz NY, Tanrıkulu F, Yılmaz D, Kuzgun H. Attitudes of intensive care nurses towards evidence-based nursing. IJSR 2018;8(1):138-143.

16. Küçükoğlu S, Bükecik T, Aytekin A, Çeleb A. Acil birimlerde çalışan hemşirelerin adli vakayla ilgili yaklaşımları ve kanıta dayalı uygulamaları. Türkiye Klinikleri Adli Tıp ve Adli Bilimler Dergisi 2017;14(1):1-8.

17. Yılmaz D, Düzgün F, Dikmen Y. Hemşirelerin kanıta dayalı hemşireliğe yönelik tutumlarının incelenmesi. Acıbadem Üniversitesi Sağlık Bilimleri Dergisi 2018;10:3-6.

18. Durmuş M, Gerçek A, Çiftci N. Sağlık çalışanlarının problem çözme becerilerinin kanıta dayalı tutum algıları üzerindeki etkisi. Akademik Sosyal Araştırmalar Dergisi 2017;5(52):648-661.

19. Daştan B, Hintistan S. Dahiliye kliniklerinde çalışan hemşirelerin kanıta dayalı hemşireliğe yönelik tutumlarının belirlenmesi: kırsal bölge örneği. Ordu University Journal of Nursing Studies 2018;1(1):1-9.

20. André B, Aune AG, Brænd JA. Embedding evidence-based practice among nursing undergraduates: results from a pilot study. Nurse Educ Pract 2016;18:30-5.

21. Scurlock-Evans L, Upton P, Rouse J, Upton D. To embed or not to embed? Alongitudinal study explorin the impact of curriculum design on the evidence-basedpractice profiles of UK pre-registration nursing students. Nurse Educ Today 2017;58:12-18.

22. Mena-Tudela D, González-Chordá VM, Cervera-Gasch A, Maciá-Soler ML, Orts-Cortés MI. Effectvieness of an evidence-based practice educational intervention with second-year nursing students. Rev. Latino-Am. Enferm 2018; 26:3026.

23. Balakas K, Smith JR. Evidence-based practice and quality improvement innursing education. J. Perinat. Neonatal Nurs 2016;30(3):191-194.

24. Mashiach EM. Implementation of evidence-based nursing practice: nurses' personal and Professional factors? J Adv Nurs 2011;67:33-42.

25. Arslan S, Şener DK, Küçük Ö. Pediatri kliniğinde çalışan hemşirelerin kanıta dayalı uygulamalara ilişkin görüşleri. Yıldırım Beyazıt Üniversitesi Sağlık Bilimleri Fakültesi Hemşirelik E-Dergisi 2015;3:1-9.

26. Merih YD, Potur DC, Esencan TY. Doğum sonu kliniklerinde çalışan ebe ve hemşireler kanıta dayalı uygulamaların neresinde? Sağlık ve Hemşirelik Yönetimi Dergisi 2017;1(4):8-14.

27. Zhou F, Hao Y, Guo H, Liu H. Attitude, knowledge, and practice on evidence-based nursing among registered nurses in traditional Chinese medicine hospitals: a multiple center cross-sectional survey in China. Evid Based Complement Alternat Med 2016;1:1-8.

28. Stokke K, Olsen NR, Espehaug B, Nortvedt MW. Evidence based practice beliefs and implementation among nurses: a cross-sectional study. BMC Nursing 2014;13(8):1-10.

29. Ammouri AA, Raddaha AA, Dsouza P, Geethakrishnan R, Noronha JA, Obeidat AA, Shakman L. Evidence-based practice: knowledge, attitudes, practice and perceived barriers among nurses in Oman. SQUMJ 2014;14(4):537-45.

30. Fiset VJ, Graham ID, Davies BL. Evidence-based practice inclinical nursing education: a scoping review. J Nurs Educ 2017; 56(9):534-541.

31. Şenyuva E. Hemşirelik eğitimi ve kanıta dayalı uygulamalar. F.N. Hem. Dergisi 2016;24:59-65.

32. Youssef NF, Alshraifeen A, Alnuaimi K, Upton P. Egyptian and Jordanian nurse educators' perception of barriers preventing the implementation of evidence-based practice: a cross-sectional study. Nurse Educ Today 2018;64:33-41.

33. Malik G, McKenna L, Plummer V. Perceived knowledge, skills, attitude and contextual factors affecting evidence-based practice among nurse educators, clinical coaches and nurse specialists. Int J Nurs Pract 2015;21(2):46-57.

34. Reid J, Briggs J, Carlisle S, Scott D, Lewis C. Enhancing utility and understanding of evidence based practice through undergraduate nurse education. BMC Nursing 2017;16(58):1-3.

35. Alshehri MA, Alalawi A, Alhasan H, Stokes E. Physiotherapists' behaviour, attitudes, awareness, knowledge and barriers in relation to evidence-based practice implementation in Saudi Arabia: a cross-sectional study. JBI Evidence Implementation 2017;15(3):127-141.

\section{Kisaltmalar}

KDHYTÖ: Kanıta Dayalı Hemşireliğe Yönelik Tutum Ölçeği, KDU: Kanıta dayalı uygulama 
EK I: Hemşire Bilgi Formu

\begin{tabular}{|c|c|}
\hline 1. & Cinsiyet \\
\hline a) & Kadın \\
\hline b) & Erkek \\
\hline 2. & Yaşınız .... \\
\hline 3. & Yaş Grubu \\
\hline a) & 25 yaş ve $\downarrow$ \\
\hline b) & $26-36$ yaş \\
\hline c) & 37 ve $\uparrow$ \\
\hline 4. & Eğitim Düzeyiniz? \\
\hline a) & Lise \\
\hline b) & Ön lisans \\
\hline c) & Lisans \\
\hline d) & Lisans üstü \\
\hline 5. & Medeni Durumunuz? \\
\hline a) & Evli \\
\hline b) & Bekâr \\
\hline 6. & Çalışma yılı ......... \\
\hline a) & $1-6$ y1l \\
\hline b) & $7-12$ y1l \\
\hline c) & $13-18$ y1l \\
\hline d) & 19 ve $\uparrow$ \\
\hline 7. & Çalışma Pozisyonunuz? \\
\hline a) & Servis hemşiresi \\
\hline b) & Sorumlu hemşire \\
\hline 8. & Çalıştığınız Vardiya Türü? \\
\hline a) & $8-16$ \\
\hline b) & $16-08$ \\
\hline c) & $08-08 / 24-08$ \\
\hline 9. & Çalışma şekliniz? \\
\hline a) & Kadrolu \\
\hline b) & Sözleşmeli \\
\hline
\end{tabular}

10. Hemşirelik uygulamalarında kullanılan bilgi kaynaklarından uygun olanı işaretleyiniz?
a) Hizmet içi eğitim
b) Hemşirelik eğitimi sırasında alınan bilgiler
c) Deneyimli hemşirelerden alınan bilgiler
d) Internet
e) Bilimsel dergi-kitaplar
11. Kanıta dayalı uygulamaları kullanma durumunuz?
a) Evet
b) Hayır

12.Kaynaklara ulaşmayı bilme durumunuz?
a) Evet
b) Hayır

13.Bilimsel toplantılara katılma durumunuz?
a) Evet
b) Hayır

14.Bilimsel araştırma yapma durumunuz?
a) Evet
b) Hayır

15.Herhangi bir mesleki derneğe üye olma durumunuz?
a) Evet
b) Hayır

16.Yabanc1 dil bilme durumunuz?
a) Evet
b) Hayır 
Araştırma

\section{EK II: Kanıta Dayalı Hemşireliğe Yönelik Tutum Ölçeği}

(1= Hiç katılmıyorum, 2= Katılmıorum, 3= Biraz katılıyorum, 4=Katılıyorum, 5= Tamamen katılıyorum)

\begin{tabular}{|c|c|c|c|c|c|c|c|}
\hline No & Madde & 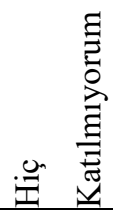 & 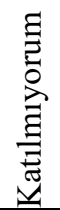 & : & 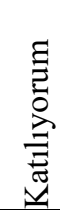 & 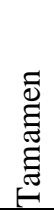 & 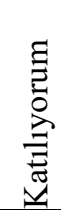 \\
\hline 1 & $\begin{array}{l}\text { Kanıta dayalı hemşireliğin, hemşireliğin günlük } \\
\text { uygulamalarının önemli bir parçası olmasından } \\
\text { memnun olurum. }\end{array}$ & 1 & 2 & 3 & 4 & & 5 \\
\hline 2 & $\begin{array}{l}\text { Uyguladığım bakımla ilgili güçlü bilimsel kanıt } \\
\text { bulmaktan memnun olurum. }\end{array}$ & 1 & 2 & 3 & 4 & & 5 \\
\hline 3 & $\begin{array}{l}\text { Kanıta dayalı bakım vermek, günlük çalışmalarımı } \\
\text { olumsuz etkiler. }\end{array}$ & 1 & 2 & 3 & 4 & & 5 \\
\hline 4 & $\begin{array}{l}\text { Kanıta dayalı hemşireliği uygulamak, } \\
\text { profesyonel/mesleki önceliklerim arasında değildir. }\end{array}$ & 1 & 2 & 3 & 4 & & 5 \\
\hline 5 & $\begin{array}{l}\text { İşimde/mesleğimde, kanıta dayalı hemşireliği } \\
\text { uygulamak için çaba göstermeye hazırım. }\end{array}$ & 1 & 2 & 3 & 4 & & 5 \\
\hline 6 & $\begin{array}{l}\text { Boş zamanımı, kanıta dayalı hemşireliği öğrenmek için } \\
\text { harcamaya karşıyım. }\end{array}$ & 1 & 2 & 3 & 4 & & 5 \\
\hline 7 & $\begin{array}{l}\text { Kanıta dayalı hemşireliğin kullanılması sağlık bakım } \\
\text { sonuçlarını iyileştirir. }\end{array}$ & 1 & 2 & 3 & 4 & & 5 \\
\hline 8 & $\begin{array}{l}\text { Hemşirelik araştırmalarının sonuçlarından öğrendiğim } \\
\text { bilgiyi dikkate almam. }\end{array}$ & 1 & 2 & 3 & 4 & & 5 \\
\hline 9 & $\begin{array}{l}\text { Kanıta dayalı hemşireliği çalışmalarımda kullanmak } \\
\text { istiyorum/isterdim. }\end{array}$ & 1 & 2 & 3 & 4 & & 5 \\
\hline 10 & $\begin{array}{l}\text { Sağlık bilimlerindeki araştırmalar, klinik hemşirelik } \\
\text { uygulamaları için önemli değildir. }\end{array}$ & 1 & 2 & 3 & 4 & & 5 \\
\hline 11 & $\begin{array}{l}\text { Klinik kanıta dayalı hemşirelik rehberlerinin özenli bir } \\
\text { şekilde oluşturulması için işbirliği yapmaya hazırım. }\end{array}$ & 1 & 2 & 3 & 4 & & 5 \\
\hline 12 & Bilimsel makaleleri okumaktan sıkılırım. & 1 & 2 & 3 & 4 & & 5 \\
\hline 13 & $\begin{array}{l}\text { Kanıta dayalı hemşireliğin klinik hemşirelik } \\
\text { uygulamalarında önemli bir rolü olmalıdır. }\end{array}$ & 1 & 2 & 3 & 4 & & 5 \\
\hline 14 & $\begin{array}{l}\text { Kanıta dayalı hemşirelik uygulamaları, verilen bakımın } \\
\text { standartlaşmasına yardım eder. }\end{array}$ & 1 & 2 & 3 & 4 & & 5 \\
\hline 15 & $\begin{array}{l}\text { Kanıta dayalı hemşirelik uygulamalarını, çalışmalarıma } \\
\text { entegre etmekten hoşlanmam. }\end{array}$ & 1 & 2 & 3 & 4 & & 5 \\
\hline
\end{tabular}

